\title{
Effect of Reactive Power Management of PV Inverters on Need for Energy Storage
}

\author{
Hashemi Toghroljerdi, Seyedmostafa; Østergaard, Jacob; Yang, Guangya
}

Published in:

Proceedings of the 39th IEEE Photovoltaic Specialists Conference

Publication date:

2013

Link back to DTU Orbit

Citation (APA):

Hashemi Toghroljerdi, S., Østergaard, J., \& Yang, G. (2013). Effect of Reactive Power Management of PV Inverters on Need for Energy Storage. In Proceedings of the 39th IEEE Photovoltaic Specialists Conference IEEE.

\section{General rights}

Copyright and moral rights for the publications made accessible in the public portal are retained by the authors and/or other copyright owners and it is a condition of accessing publications that users recognise and abide by the legal requirements associated with these rights.

- Users may download and print one copy of any publication from the public portal for the purpose of private study or research.

- You may not further distribute the material or use it for any profit-making activity or commercial gain

- You may freely distribute the URL identifying the publication in the public portal

If you believe that this document breaches copyright please contact us providing details, and we will remove access to the work immediately and investigate your claim 


\title{
Effect of Reactive Power Management of PV Inverters on Need for Energy Storage
}

\author{
Seyedmostafa Hashemi, Student Member, IEEE, Jacob Østergaard, Senior Member, IEEE, and \\ Guangya Yang, Member, IEEE
}

Centre for Electric Power and Energy, Technical University of Denmark, Kgs. Lyngby, 2800 Denmark

\begin{abstract}
Grid connected Photovoltaic (PV) systems are among the increasingly growing electric power generation units worldwide. The majority of new installations are expected to be residential PVs that are connected into distribution systems. However, the PV hosting capacity of low voltage (LV) grids is limited due to the voltage rise at the point of connection associated with the $P V$ feed-in current. Reactive power management using PV inverters and using the electrical energy storage systems (EESS) are amongst the main solutions for increasing the PV hosting capacity in LV grids. In this paper, a method is developed in order to examine the effect of reactive power absorption by $P V$ inverters on EESS capacity required for overvoltage prevention in $L V$ grids. Simulations show that reactive power absorption can effectively decrease the EESS capacity.
\end{abstract}

Index Terms - Energy storage, high PV penetration, overvoltage, reactive power.

\section{INTRODUCTION}

Photovoltaic (PV) is among the main renewable energy conversion technologies considered as an effective solution for replacing a part of conventional fossil fuel power stations by green energies. PV price reduction, which is the result of technological developments in solar cells manufacturing, the increase in fossil fuel and electricity prices, and governmental incentives all support the growth of PV installation in electric power systems. Although large scale PV systems are utilized as an alternative to conventional power stations, trends show that the majority of new PV installations are residential and small scale PV units which require less investment and have shorter payback time [1]. These units normally have the capacity of less than $10 \mathrm{kWp}$ and are connected to low voltage (LV) distribution grids [2].

Despite all economic and environmental advantages associated with PVs, their effects on power systems, especially distribution grids, have to be thoroughly investigated. In general, the locations of these units cannot be controlled by DNOs and their output power is also stochastic and non-dispatchable. It is well-accepted that low PV penetration in the network can decrease the power loss in LV network; however, by increasing the adoption of residential $\mathrm{PVs}$, concern regarding the reverse power flow in LV network is increasing. In addition to making problems in operation of protection systems, the reverse power flow can increase the voltage at some weak points of the network to an unacceptable value [3]-[6]. This voltage rise is one of the main limiting factors associated with increasing the PV penetration in LV networks [3], [7]-[8].

Different methods have been proposed to overcome the voltage rise problem in order to increase the PV penetration in LV grids. These methods can be divided into two main categories: first, limiting the amount of reverse power flow and second, compensating the impacts of this reverse power flow on the voltage. Prior can be carried out by means of using energy storage systems in order to store the excess energy generated by PVs and eliminate or limit the net injected power into the grid. In recent years, many researchers have investigated the advantages of using the energy storage and PV systems together [9]-[13]. Moreover, to prevent the overvoltage in the network, the effects of reverse power flow can be partly compensated by applying the methods used in voltage control of high voltage systems into the LV grids. Reactive power absorption by $\mathrm{PV}$ inverters is among the methods heeded by both researchers and system operators as an effective solution for overcoming the overvoltage problems. Because of the limitations in central control of reactive power, local reactive power control methods are widely investigated and applied in some LV grids [14]-[19]. It is worth mentioning that the distribution system characteristics differ from the higher voltage level; for example, the $\mathrm{R} / \mathrm{X}$ ratio in distribution systems is much higher than that of transmission systems. As a result, applying the high voltage methods to lower voltage systems does not necessarily have the same effects.

Although the reactive power absorption by PV inverters and energy storage applications for overvoltage prevention have been studied in some current literature, the effects of the reactive power absorption by $\mathrm{PV}$ inverters on energy storage capacity requirement for overvoltage prevention have not been analytically investigated. In this paper, a voltage sensitivity based method is proposed in order to evaluate the effects of applying local reactive power control on the capacity of energy storage units. The method is capable of modeling different PV penetration and load condition scenarios. The structure of the paper is as follows: the effects of reactive power on EESS is investigated in section II, the local reactive power management strategies are discussed in section III, the proposed method is illustrated in section IV and the simulation results are presented in section $\mathrm{V}$. 


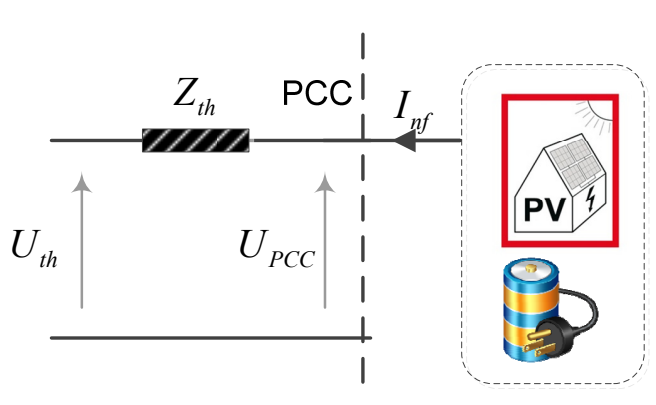

Fig. 1. The thevenin equivalent of a PV system, storage and the local load connected to a typical LV grids.

\section{The EfFects of ReACTIVE POWER ON EESS CAPACITY}

Voltage rise at the point of common coupling (PCC) is a well-known issue associated with active power feed-in by PV units. As mentioned before, reactive power absorption by PV inverters and EESS are two effective methods for preventing the overvoltage. To analysis the effects of these methods on overvoltage prevention, consider a PV system, storage and the local load connected to a typical LV grids. The thevenin equivalent of this system from PCC is shown in Fig. 1. In this figure, the $\underline{Z}_{t h}$ and $\underline{U}_{t h}$ are the thevenin impedance and thevenin voltage, respectively, $\underline{I}_{P V}$ is feed-in current of PV, $\underline{I}_{s}$ is the storage current and $\underline{I}_{L}$ models the local consumption, all in per-unit. The local voltage, $\underline{U}_{P C C}$, is determined by $\underline{U}_{t h}$, local generation and consumption. To simplify, suppose that $\underline{U}_{t h}$ is fixed at 1 p.u. with a power angle of $0^{\circ}$. The net feed-in current can be calculated by:

$$
\underline{I}_{n f}=\underline{I}_{P V}-\underline{I}_{C}-\underline{I}_{S}=\left(\frac{\underline{S}_{n f}}{\underline{U}_{P C C}}\right)^{*}
$$

where $S_{n f}$ is the net apparent power injected into the grid. By considering the active and reactive power and neglecting the power loss across the thevenin impedance, the $I_{n f}$ can be rewritten as:

$$
\underline{I}_{n f}=\left(\frac{P-j Q}{\underline{U}_{t h}}\right)=P-j Q
$$

The voltage at PCC can be calculated as

$$
\underline{U}_{P C C}=\underline{U}_{t h}+\underline{Z}_{t h} \times \underline{I}_{n f}
$$

Suppose that $\underline{Z}_{t h}=R_{t h}+j X_{t h}$. Thus

$$
\begin{aligned}
\underline{U}_{P C C}=(1+P & \left.\times R_{t h}+Q \times X_{t h}\right)+ \\
& j\left(P \times X_{t h}-Q \times R_{t h}\right)=U_{d}+j U_{q}
\end{aligned}
$$

where $U_{d}$ and $U_{q}$ are the direct-axis and quadrature-axis components of the $\underline{U}_{P C C}$, respectively. The magnitude of $\underline{U}_{P C C}$ can be calculated as in the following:

$$
\left|\underline{U}_{P c c}\right|=\sqrt{U_{d}^{2}+U_{q}^{2}}
$$

For most connection points in distribution systems, the $U_{d}^{2} \gg U_{q}^{2}$ and the quadrature-axis term can be neglected [20]; therefore the magnitude of the voltage at PCC can be simplified as follows:

$$
\left|\underline{U}_{P c c}\right|=1+P \times R_{t h}+Q \times X_{t h}
$$

According to the standards applied to LV grids, the voltage rise at the connection point should be limited to a special amount. Suppose that the maximum voltage rise is limited to 1.05 per-unit; therefore:

$$
\left(P \times R_{t h}+Q \times X_{t h}\right) \prec 0.05
$$

The maximum active power injected into the grid without overvoltage occurrence is as follows:

$$
P_{\max }=\left(\frac{0.05-Q \times X_{t h}}{R_{t h}}\right)
$$

If the PV penetration increases such that the injected power exceeds this value, the voltage will increase to an unacceptable level. To prevent the overvoltage, the EESS should be employed to store a part of generated PV power to limit the injected power into the grid. As the worst-case scenario, suppose that the load consumption is zero; then the EESS capacity can be calculated as follows:

$$
E E S S C=\int\left(P_{P V}(t)-\frac{0.05}{R_{t h}}+\frac{Q_{P V}(t) \times X_{t h}}{R_{t h}}\right) \mathrm{dt}
$$

$P_{P V}$ and $Q_{P V}$ are active and reactive power generated by PV, respectively. It can be seen that without any reactive power absorption, the storage should curtail the injected power at lower level and the storage capacity will increase. In addition, the severity effect of reactive power management on the voltage depends mainly on $\mathrm{X} / \mathrm{R}$ ratio; so in $\mathrm{LV}$ grid with lower $\mathrm{X} / \mathrm{R}$ ratio, this effect is lower and vice versa.

\section{LOCAL REACtIVE POWER MANAGEMENT STRATEGIES FOR GRID VOLTAGE SUPPORT}

The local reactive power absorption methods can be divided mainly into three categories, namely, fixed power factor (fixed $\cos \varphi$ ), reactive power as a function of voltage in the connection point $(Q(U))$ and power factor as a function of injected active power $(\cos \varphi(\mathrm{P}))$. These methods have simple architectures and they can be implemented in the PV inverters by using a fixed set-point or droop characteristics. The schematics of these methods are illustrated in Fig. 2.

In $Q(U)$ method, the voltage of the PV connection point is considered as the reference for the droop control. In this method, the reactive power absorption is implemented only 
when the PCC voltage is high. As a result, the inverters do not absorb reactive power when the PCC voltage is not high and this reduces the loss caused by reactive power absorption in the system. However, in high PV penetration conditions, the inverters located near the transformer do not sense the overvoltage and not participate in reactive power management as effectively as possible [19].

In the fixed PF method, the reactive power is proportional to the generated active power by PVs. In this method, regardless of the PV output, a fixed value is set as power factor and implemented into the controller. The drawback of this method is that during low PV generation time, the PV generation is consumed by local loads and the risk of overvoltage becomes low; however, the reactive power absorption is still applied and the grid loss may increase in this condition. To overcome this problem, the $\cos \varphi(\mathrm{P})$ method can be applied to the PV controller. In this method, the droop can be set to the values in such a way that during low PV generation, no reactive power absorption is carried out by PV inverters. In addition, the power factor and therefore, the reactive power are proportional to the generated active power.

In general, these methods have the drawback that they can increase the power loss and the line's congestion. In this paper, the main purpose is to examine the effects of reactive power absorption by PV inverters on EESS capacity and their effects on power loss are not considered. As a result, only fixed PF method is considered and simulated in the simulation results section.
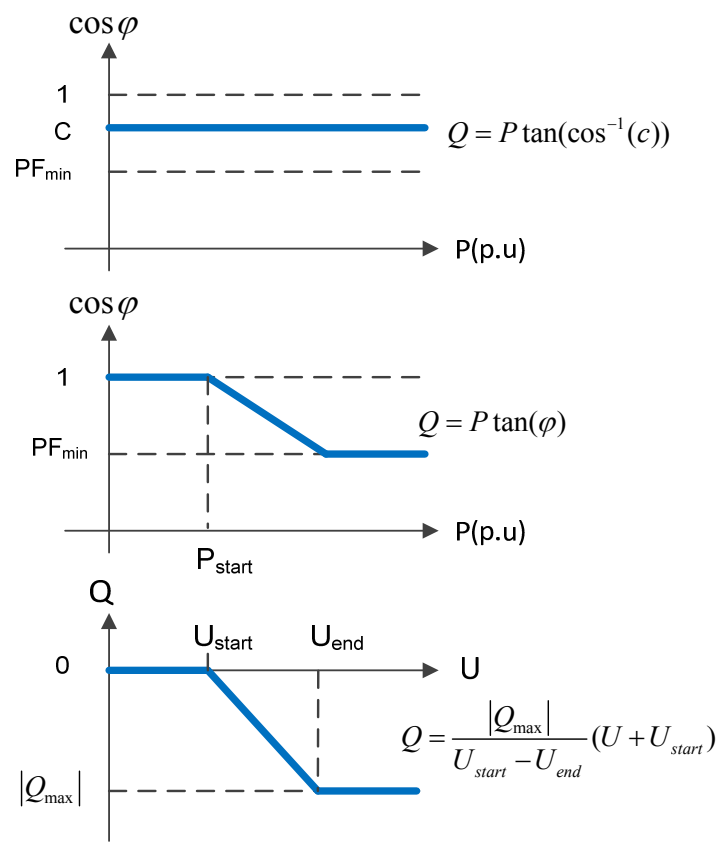

Fig. 2. The schematics of the local reactive power absorption methods.

\section{METHOD DESCRIPTION}

PV penetration can be defined in different ways such as total installed PV capacity compared with the peak load demand [3], total PV generation to total generation [2], etc. In this paper, $\mathrm{PV}$ penetration is defined as the number of customers with PV system to the total number of customer. The sensitivity analysis is used as an effective tool which requires less computational time than load flow calculations. By using a well-conditioned Jacobian matrix derived from power flow equations which are related to Newton-Raphson (NR) load-flow solution, the voltage sensitivity matrix can be extracted as in the following:

$$
\begin{aligned}
& {\left[\begin{array}{c}
\Delta V_{2} \\
\cdots \\
\Delta V_{n-1} \\
\Delta V_{n}
\end{array}\right]=\left[\begin{array}{cccc}
S_{V P 2,2} & \ldots & S_{V P 2, n-1} & S_{V P 2, n} \\
\ldots & \ldots & \ldots & \ldots \\
& & & \\
S_{V P n-1,2} & \ldots & S_{V P n-1, n-1} & S_{V P n-1, n} \\
S_{V P n, 2} & S_{V P n, 3} & S_{V P n, n-1} & S_{V P n, n}
\end{array}\right] \times\left[\begin{array}{c}
\Delta P_{2} \\
\cdots \\
\\
\Delta P_{n-1} \\
\Delta P_{n}
\end{array}\right]} \\
& +\left[\begin{array}{cccc}
S_{V Q 2,2} & \ldots & S_{V Q 2, n-1} & S_{V Q 2, n} \\
\ldots & \ldots & \ldots & \ldots \\
S_{V Q n-1,2} & \ldots & S_{V Q n-1, n-1} & S_{V Q n-1, n} \\
S_{V Q n, 2} & S_{V Q n, 3} & S_{V Q n, n-1} & S_{V Q n, n}
\end{array}\right] \times\left[\begin{array}{c}
\Delta Q_{2} \\
\cdots \\
\Delta Q_{n-1} \\
\Delta Q_{n}
\end{array}\right]
\end{aligned}
$$

The bus voltage can be calculated as follows:

$$
V_{n}=\Delta V_{n}+V_{S}
$$

where $V_{S}$ is the voltage of the swing or slack bus. The level of voltage rise in LV distribution systems due to high residential PV penetration depends mainly on the net power injected into the grid by each customer located at that distribution grid. This remaining power depends on both PV generation and load consumption in bus $n$ and it can be defined as follows:

$$
R P_{n}(t)=P_{P V, n}(t)-P_{L, n}(t)
$$

$P_{P V}$ and $P_{L}$ are the PV generation and load consumption, respectively. By using (10), (11) and (12), the voltage profile of bus $n$ can be determined as in the following:

$$
\begin{aligned}
V_{n}(t)=V_{s}(t)+\sum_{g=2}^{m}\left(S_{V P n, g} \times R P_{g}(t)+\right. \\
S_{V Q n, g} \times\left(Q_{g}(t)+Q_{P V}(t)\right)
\end{aligned}
$$

In this equation, $m$ is the total number of buses in the system and $Q_{g}(t)$ is the injected reactive power into the grid by local loads. $Q_{P V}(t)$ can be determined based on the selected reactive power management method. In the fixed PF method, 
$P F=\cos (\varphi)=c$, and $Q=P \tan (\varphi)$, then (13) can be rewritten as follows:

$$
\begin{aligned}
& V_{n}(t)=V_{s}(t)+\sum_{g=2}^{m}\left(S_{V P n, g} \times R P_{g}(t)+\right. \\
& \left.S_{V Q n, g} \times\left(Q_{g}(t)+P_{P V, g}(t) \times \tan \left(\cos ^{-1}(\mathrm{c})\right)\right)\right)
\end{aligned}
$$

where $P_{P V, g}(t)$ is active power of PVs located at bus $g$. By adding special amount of EESS to the selected bus, the injected power into the grid will change. The required storage to curtail the $R P$ at specific level $P$ can be calculated as in the following:

$$
\text { Storage }_{n}^{P}=\int_{R P_{n}(t) \succ P} R P_{n}(t) d t
$$

The minimum storage required to prevent the overvoltage can be calculated by solving the following equation:

$$
\begin{gathered}
\text { Minimize } \sum_{i=2}^{m} \text { Storage }_{i}^{P} \\
\text { S.t. } \\
V_{i}(t)<V_{\max }
\end{gathered}
$$

\section{Simulation RESULtS}

To examine the effect of reactive power absorption by PV inverters on EESS capacity, a typical low voltage feeder of Bornholm with 52 customers is selected for simulations, as depicted in Fig. 3. The feeder is supplied by one MV/LV, 100 $\mathrm{kVA}, 0.4 \mathrm{kV}$ Transformer. Simulations are carried out for different PV penetrations and for all cases, the power factor of PV inverters is considered as 0.9. The load profile for all customers is considered the same as shown in Fig. 4. The net injected active power into the grid differs due to the PV penetration. A typical remaining power curve and its related PV generation are also shown in Fig. 4. The slack bus voltage is considered to be fixed at $230 \mathrm{~V}$ and the maximum voltage rise is limited to $5 \%$.

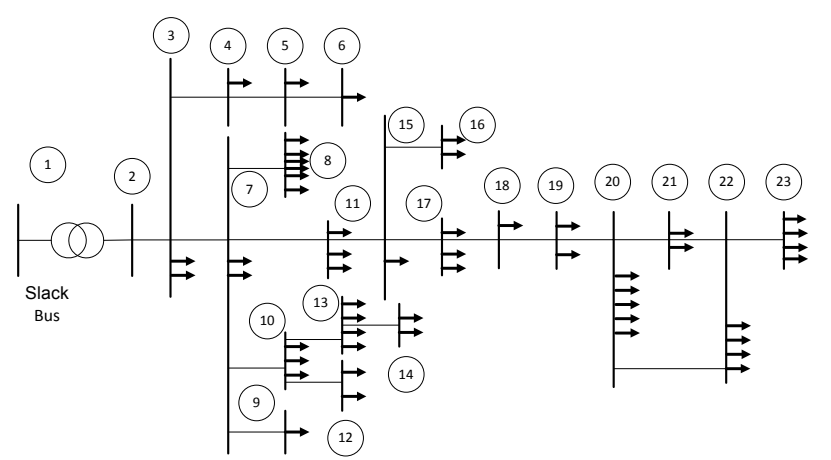

Fig. 3. Single-line diagram of the investigated low voltage grid.

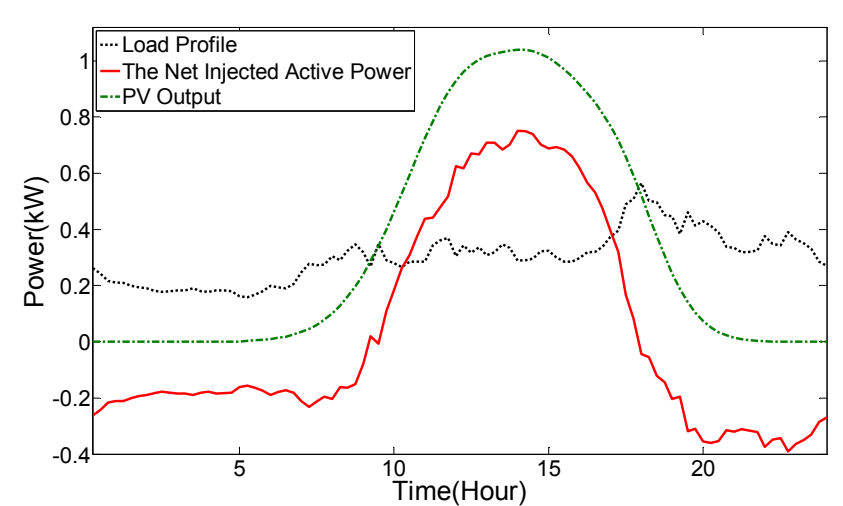

Fig. 4. The net injected active power and its related PV generation and load consumption.

Simulations show that the required EESS for overvoltage prevention is different according to the location of customers. The capacity is less for buses located nearer the transformer as they have less sensitivity to the active power. In addition, the reactive power absorption by PV inverters can decrease the EESS capacity. For example, the average EESS capacity in $50 \% \mathrm{PV}$ penetration without reactive power absorption is 4.4 $\mathrm{kWh}$; however, this amount is reduced to $2.2 \mathrm{kWh}$ in the condition of reactive power absorption. It shows around $50 \%$ decrease in EESS capacity. In average, by reactive power management, the EESS capacity required for overvoltage prevention is decreased around 30 percent.

\section{CONCLUSION}

In this paper, a voltage sensitivity based method was proposed in order to evaluate the effects of applying local reactive power control on the capacity of energy storage units. The method is capable of modeling different PV penetration and load condition scenarios. Simulations showed that the required EESS for overvoltage prevention is different according to the location of customers. The capacity was less for buses located nearer the transformer as they have less sensitivity to the active power. In addition, the reactive power absorption by PV inverters can decrease the EESS capacity. In average, by reactive power management, the EESS capacity required for overvoltage prevention was decreased around 30 percent.

\section{ACKNOWLEDGEMENT}

This work was supported in part by PVNET.dk project sponsored by Energinet.dk under the Electrical Energy Research Program. 
TABLE I

EESS CAPACITY IN DIFFERENT PV PENETRATION CONDITIONS

\begin{tabular}{|c|c|c|c|c|c|c|c|c|c|c|}
\hline $\begin{array}{c}\text { PV Penetration } \\
\text { (\%) }\end{array}$ & \multicolumn{8}{|c|}{$\begin{array}{c}\text { Capacity (kWh) per Customer Without } \\
\text { Reactive Power Management }\end{array}$} & $\begin{array}{c}\text { Capacity (kWh) per Customer With } \\
\text { Reactive Power Management }\end{array}$ \\
\hline 100 & 0 & 6.3 & 25.8 & 35.7 & 19.1 & 0 & 3.8 & 21.7 & 30.6 & 15.7 \\
\hline 90 & 0 & 4.8 & 20.5 & 30.8 & 15.9 & 0 & 2.7 & 17.2 & 25.5 & 12.7 \\
\hline 80 & 0 & 3.3 & 16.2 & 25.7 & 12.8 & 0 & 2.1 & 12.9 & 20 & 9.8 \\
\hline 70 & 0 & 2.5 & 11.5 & 20.2 & 9.8 & 0 & 1.1 & 8.5 & 15.4 & 7.1 \\
\hline 60 & 0 & 1.7 & 7.6 & 14.6 & 6.9 & 0 & 0.6 & 5.4 & 9.8 & 4.5 \\
\hline 50 & 0 & 0.6 & 4.2 & 9.7 & 4.2 & 0 & 0.4 & 2.60 & 4.7 & 2.2 \\
\hline 40 & 0 & 0.2 & 1.5 & 4.2 & 1.8 & 0 & 0.1 & 0.3 & 0.8 & 0.3 \\
\hline
\end{tabular}

\section{REFERENCES}

[1] S. Eftekharnejad, V. Vittal, G. T. Heydt, B. Keel, and J. Loehr, "Impact of Increased Penetration of Photovoltaic Generation on Power Systems," IEEE Trans. Power Systems, vol. 28, pp. 893-901, 2013.

[2] K. F. Katiraei and J. R. Aguero, "Solar PV Integration Challenges," IEEE Power and Energy Magazine, vol. 9, pp. 62-71, 2011.

[3] M. E. Baran, H. Hooshyar, S. Zhan, and A. Huang, "Accommodating High PV Penetration on Distribution Feeders," IEEE Trans. Smart Grid, vol. 3, pp. 1039-1046, 2012.

[4] M. Thomson and D. G. Infield, "Impact of Widespread Photovoltaics Generation on Distribution Systems," IET Renewable Power Generation, vol. 1, pp. 33-40, 2007.

[5] R. A. Shayani and M. A. G. de Oliveira, "Photovoltaic Generation Penetration Limits in Radial Distribution Systems," IEEE Trans. Power Systems, vol. 26, pp. 1625-1631, 2011.

[6] R. Tonkoski, L. A. C. Lopes, and T. H. M. El-Fouly, "Coordinated Active Power Curtailment of Grid Connected PV Inverters for Overvoltage Prevention," IEEE Trans. Sustainable Energy, vol. 2, pp. 139-147, 2011.

[7] R. Tonkoski, D. Turcotte, and T. H. M. El-Fouly, "Impact of High PV Penetration on Voltage Profiles in Residential Neighborhoods," IEEE Trans. Sustainable Energy, vol. 3, pp. 518-527, 2012.

[8] A. Canova, L. Giaccone, F. Spertino, and M. Tartaglia, "Electrical Impact of Photovoltaic Plant in Distributed Network," IEEE Trans. Industry Applications, vol. 45, pp. 341-347, 2009.

[9] Y. Ru, J. Kleissl, and S. Martinez, "Storage Size Determination for Grid-Connected Photovoltaic Systems," IEEE Trans. Sustain. Energy, vol. 4, pp. 68-81, 2013.

[10] S. Vazquez, S. M. Lukic, E. Galvan, L. G. Franquelo, and J. M. Carrasco, "Energy Storage Systems for Transport and Grid Applications," IEEE Trans. Industrial Electronics, vol. 57, pp. 3881-3895, 2010.

[11] H. Beltran, E. Bilbao, E. Belenguer, I. Etxeberria-Otadui, and P. Rodriguez, "Evaluation of Storage Energy Requirements for
Constant Production in PV Power Plants," IEEE Trans. Industrial Electronics, vol. 60, pp. 1225-1234, 2013.

[12] H. Beltran, E. Perez, N. Aparicio, and P. Rodriguez, "Daily Solar Energy Estimation for Minimizing Energy Storage Requirements in PV Power Plants," IEEE Trans. Sustain. Energy, vol. PP, pp. 1-8, 2012.

[13] H. Sugihara, K. Yokoyama, O. Saeki, K. Tsuji, and T. Funaki, "Economic and Efficient Voltage Management Using Customer-Owned Energy Storage Systems in a Distribution Network With High Penetration of Photovoltaic Systems," IEEE Trans. Power Systems, Early Access Article.

[14] Y. Ruifeng and T. K. Saha, "Investigation of Voltage Stability for Residential Customers Due to High Photovoltaic Penetrations," IEEE Trans. Power Systems, vol. 27, pp. 651662, 2012.

[15] P. M. S. Carvalho, P. F. Correia, and L. A. F. Ferreira, "Distributed Reactive Power Generation Control for Voltage Rise Mitigation in Distribution Networks," IEEE Trans. Power Systems, vol. 23, pp. 766-772, 2008.

[16] R. A. Mastromauro, M. Liserre, T. Kerekes, and A. Dell'Aquila, "A Single-Phase Voltage-Controlled GridConnected Photovoltaic System with Power Quality Conditioner Functionality," IEEE Trans. Industrial Electronics, vol. 56, pp. 4436-4444, 2009.

[17] J. C. Vasquez, R. A. Mastromauro, J. M. Guerrero, and M. Liserre, "Voltage Support Provided by a Droop-Controlled Multifunctional Inverter," IEEE Trans. Industrial Electronics, vol. 56, pp. 4510-4519, 2009.

[18] M. H. J. Bollen and A. Sannino, "Voltage control with inverter-based distributed generation," IEEE Trans. Power Delivery, vol. 20, pp. 519-520, 2005.

[19] E. Demirok, G. Casado, x, P. lez, K. H. B. Frederiksen, D. Sera, et al., "Local Reactive Power Control Methods for Overvoltage Prevention of Distributed Solar Inverters in LowVoltage Grids," IEEE Journal of Photovoltaics, vol. 1, pp. 174-182, 2011.

[20] T. Stetz, F. Marten, and M. Braun, "Improved Low Voltage Grid-Integration of Photovoltaic Systems in Germany," IEEE Trans. Sustainable Energy, vol. 4, pp. 534-542, 2013. 